\title{
ALEXANDRIA
}

Revista de Educação em Ciência e Tecnologia

ALEXANDRIA

\section{Isto é (Ou Não é) um Cachimbo?}

Is this (Or is Not) a Pipe?

\section{Thiago Pedro Pinto}

a Instituto de Matemática, Universidade Federal de Mato Grosso do Sul, Campo Grande, Brasil - thiago.pinto@ufms.br

\section{Palavras-chave: \\ Ficção e realidade. Representação. Jogos de linguagem.}

\section{Keywords:}

Fiction and reality.

Representation.

Language games
Resumo: Neste texto abordamos a usual separação entre representante e representado, entre ficção e realidade, bem como a relação destas com "a verdade". Estes aspectos são evidenciados para discutirmos implicações diretas para a sala de aula de Matemática e para o campo de pesquisa da Educação Matemática, mais especificamente para o ramo da História da Educação Matemática. Nossos posicionamentos estão fortemente apoiados em nossas leituras dos escritos de Ludwig Wittgenstein em sua segunda fase, que foge da questão que intitula este trabalho, propondo outras no lugar. Esta fase tem como obra principal o livro Investigações Filosóficas. Desta forma, a noção de jogos de linguagem e semelhanças de família são centrais em nossa discussão, que tenta abandonar o essencialismo e uma visão Platonista do conhecimento. A separação entre ficção e realidade é deixada para trás, no que se refere à epistemologia, esta separação não mais faz sentido, sendo então colocada de lado para se pensar em potencialidades e efeitos da produção acadêmica.

\begin{abstract}
In this text we approach the usual separation between representation and represented, between fiction and reality, as well as their relationship with "truth". These aspects are evidenced to discuss implications for the Mathematics classroom and for the Mathematics Education, specifically for the History of Mathematics Education. Our positions are strongly supported in Ludwig Wittgenstein's writes in his second phase, having as main work the book Philosophical Investigations. In this way, the notion of language games and family similarities are central to our discussion, which attempts to abandon essentialism and a Platonist view of knowledge. The separation between fiction and reality is left behind, as far as epistemology is concerned, this separation no longer makes sense, and then we propose to think of the potentialities and effects of our academic production.
\end{abstract}




\section{Isto não é um Cachimbo?}

Este título remete automaticamente, a muitos de nós, à pintura de René François Ghislain Magritte [pintor surrealista belga (1898 - 1967)], que de alguma forma parece provocar a questão de 'o quão enganadoras podem ser as imagens':

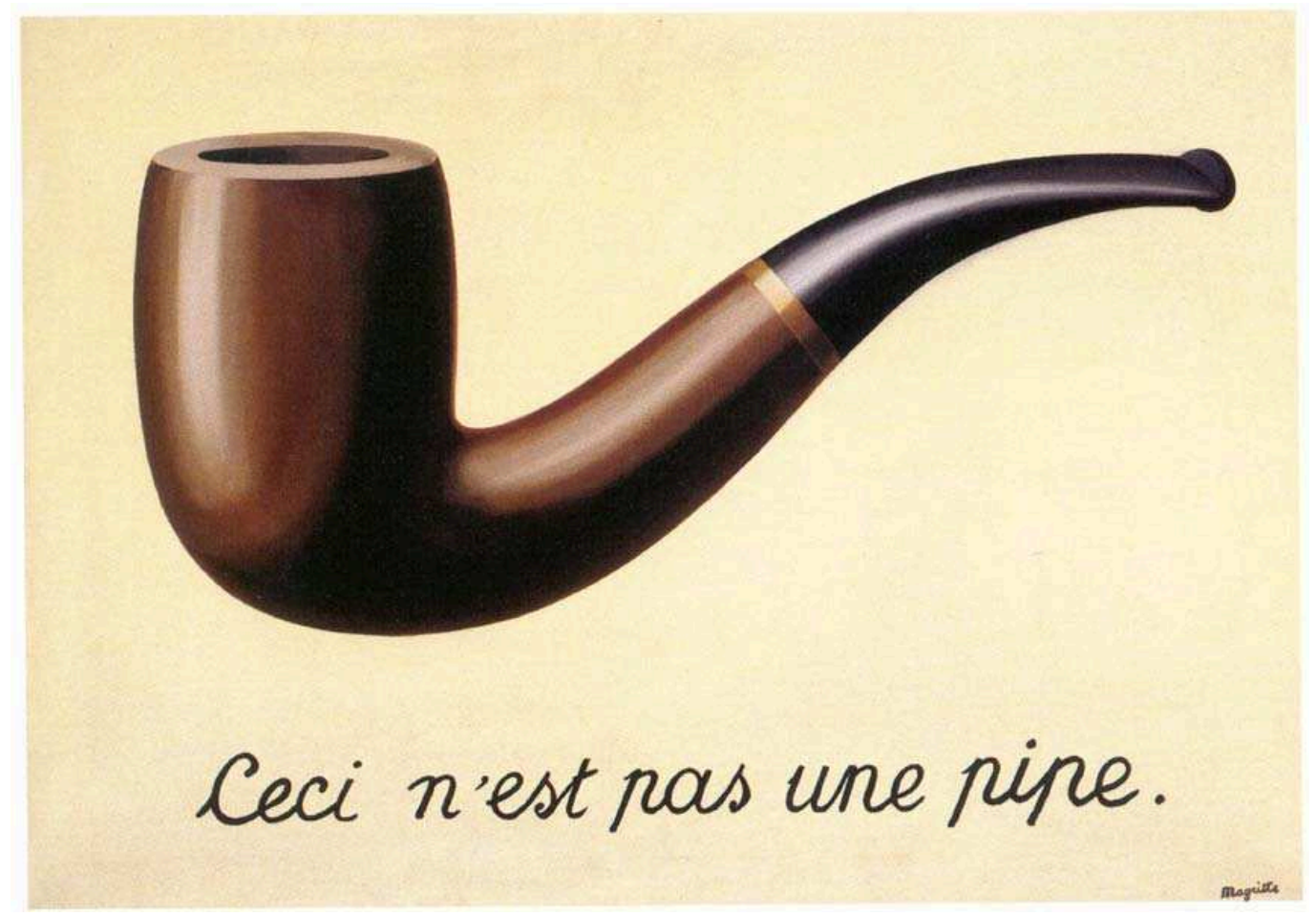

Figura 01 - La trahison des images

Fonte: René Magritte (1929)

Ao mostrar a pintura daquilo que convencionalmente chamamos de 'cachimbo' junto a uma legenda que diz 'Isto não é um cachimbo', somos colocados a questionar': "isso é uma outra coisa que não um cachimbo, uma casa, um animal, a representação é enganadora?", ou seria esta advertência um imperativo para que alguém não utilizasse esta pintura para fumar? Uma necessidade para que as pessoas de fato não confundissem o objeto 'pintura' com o objeto que "serve para fumar' ${ }^{\text {? }}$ Estas não nos parecem ser preocupações legítimas, tão pouco acreditamos que estas questões sejam as que tenham motivado a pintura e "provocação" do autor.

Há ainda outra possibilidade, a de que o autor queira evidenciar que a pintura (representação) difere do real ou ideal (representado). Parece-nos que sua questão ou objetivo está mais relacionado a esta última, a uma diferenciação entre signo e significado, entre

\footnotetext{
${ }^{1}$ Este trabalho tenta, na medida do possível, e flertando com os limites da publicação acadêmica, ser pessoal, questionador e, algumas vezes, prolixo. Afinal, como mostraremos ao longo do texto, sintetizar já é um outro jogo, do qual queremos nos afastar neste momento.

2 Apresentamos neste texto um uso exagerado de aspas, especialmente com duas funções: a de relativizar o uso (significado) das palavras e expressões, como fazemos na expressão oral e também para inserir palavras como "colagens" de falas vindas de outros locais, como faz a lógica ao enunciar 'A', este 'A' não tem na frase a mesma função de um artigo, por exemplo.
} 
representação e representante e, por que não dizer, entre ficção e realidade. Há, como já sinalizou Michel Foucault (1973), inúmeras possibilidades de interpretação desta obra e de outras que se desdobram dela.

No senso comum, a divisão entre "real" e qualquer uma das expressões: ficção, imaginário, ideal, utópico, representação, parecer ser rígida e se estabelece como dicotômica, conjuntos disjuntos, sem a menor possibilidade de interação, a verdade que flerta com a ficção é simplesmente chamada de mentira, bem como aquilo intitulado de real quase sempre tem o estatuto de verdadeiro. Realidade se torna, em muitas falas, o sentido de "é verdade", "é o correto": "na realidade foi isso e não aquilo que aconteceu".

As charges de Charlie Hebdo têm causado, há algum tempo, grande furor em toda comunidade atingida por suas críticas - sempre ácidas. Recentemente, a antropóloga e escritora brasileira Yvonne Maggie, de renomado currículo científico, escreveu no portal G1 trazendo Magritte para a discussão sobre esse tema e sobre os ataques jihadistas em resposta às charges veiculadas no "jornal satírico francês"” Charlie Hebdo:

\begin{abstract}
Em 1929, o artista surrealista belga René Magritte fez uma obra fundamental que nos faz pensar sobre o objeto em si e sua representação. É sobre representação e não sobre o objeto do pensamento em si que incide a charge. A charge é como o quadro de Magritte, uma representação. "Ceci n'est pas une pipe" (Isto não é um cachimbo) foi uma imagem revolucionária e continua sendo. Assim é que penso as charges nos jornais do mundo todo e do "Charlie Hebdo". Entre o objeto do pensamento e a representação existe um espaço. Espaço de reflexão e de interpretação. [...]. (MAGGIE, 2015, negrito nosso)
\end{abstract}

Acreditamos que é necessário problematizar esta divisão que coloca de um lado o 'mundo da representação' (da linguagem, das artes, da literatura etc.) e do outro o 'mundo real' (físico, biológico, comportamental etc.) com seus objetos.

Algumas questões atuais como o preconceito religioso, racial, social ou regional, o bullying e intolerância praticados, especialmente, na rede mundial de computadores, levantam a questão: “em que medida estas 'representações' não afetam também as vidas 'reais' das pessoas?", visto que são aspectos da linguagem que interferem diretamente no mundo físico.

Da mesma forma, o fluxo de notícias contraditórias sobre determinados assuntos, principalmente quanto aos temas políticos, também nos faz questionar uma (im)possível objetividade da imprensa em noticiar "o ocorrido". Frase comum nas redes sociais: "ao jornalista cabe informar, não dar opinião", seria possível isentá-lo de tal ação? Há uma possibilidade de representar o "fato em si"?

Para aquém, muito aquém das questões apresentadas acima, nos interessa a forma como estes 'mundos' veem sendo separados em nossas práticas cotidianas e em tantos

\footnotetext{
${ }^{3}$ Esta foi a nomeação que se encontra disponível em diversos sites da internet, a adotamos aqui por justamente entender que o termo empregado "satírico" corrobora com o tipo de argumentação tecida por Yvonne Maggie na sequência.
} 
discursos acadêmicos, especialmente os ligados ao ensino e à Educação Matemática e uma possibilidade de olhar "para outro lado", esvaindo esta questão. Tal distanciamento entre "mundos" coloca, inclusive, uma suposta possibilidade de existência de um sem o outro, ou seja, podemos ter um mundo "imaginário", "ficcional", dos textos e das criações artísticas, para além da realidade e, por outro lado, um mundo "verdadeiro", "real", que independe destas representações (o cachimbo de Magritte é uma pintura, uma ficção, não o objeto real!).

As leis que nos protegem da ofensa, da calúnia, do preconceito e do bullying vão no sentido contrário, apontam a possibilidade de "violência simbólica", que não está (a priori) no 'mundo físico', e seu cumprimento se exerce, nos casos mais graves, à restrição de liberdade deste 'corpo físico' - parece que há aqui uma interseção.

Nosso foco último, além destes casos $\operatorname{cotidianos}^{4}$, incide sobre a sala de aula de Matemática e como ela aborda ou tem abordado esta questão. Estamos aqui, declaradamente, interessados na(s) matemática(s) em situações de ensino e aprendizagem, em processos formais ou não.

Para a Matemática, de forma geral, há as chamadas correntes filosóficas, que tentam responder "o que é a matemática", qual o seu estatuto epistemológico. De forma sintética, mas suficiente para iniciarmos esta discussão, encontramos em Davis e Hersh (1985) a nomeação de algumas destas correntes: Platonismo, Formalismo e Construtivismo (C.f. BARKER, 1976; SANPPER, 1984).

Cada uma dessas correntes propunha certa visão sobre o conhecimento matemático, sobre a natureza de seus objetos e sobre a relação da matemática com o mundo empírico, de forma muito simplificada: para os "plantonistas" o conhecimento matemático existe independente do nosso acesso a ele, vamos, com o desenvolvimento, "descobrindo" as coisas que "já existem desde sempre"; o conhecimento está além do mundo físico, independe dele. A famosa frase de Galileu “A matemática é o alfabeto com qual Deus escreveu o universo" seria uma boa ilustração deste movimento.

Já para os formalistas, não há "objetos” matemáticos. A matemática é uma rede de conhecimento que se sustenta em axiomas, definições e teoremas, que independem das nossas experiências empíricas. O uso da matemática para tais experiências já "foge” da prática do matemático, já se está aí fazendo outra coisa. Um dos nomes associados ao formalismo matemático é o de David Hilbert, que recria a axiomática da Geometria, cobrindo algumas lacunas lógicas de Os Elementos.

\footnotetext{
4 O cotidiano e os usos ordinários da linguagem serão trazidos à tona neste texto, tentando aqui, deliberadamente, nos aproximarmos do modo como Wittgenstein discute a linguagem. Por conta disso, haverá inúmeras questões colocadas a titulo de reflexão.
} 
Por fim, os construtivistas, se opondo aos anteriores, limitam a matemática ao que pode ser efetivamente construído - ligado ao empírico. Processos que não possuem "fim”, como construções de conjuntos com infinitos elementos são desconsiderados. Assim, o Conjunto dos Números Reais ou a Hipótese de Cantor, por exemplo, são meras brincadeiras de palavras (Davis \& Hersh, 1985, p. 361), não fazem parte da Matemática. O grande número de críticas a esta corrente se deu, principalmente, pelas limitações que ela impunha a matemática, reduzindo-a sobremaneira.

Podemos ver como cada uma das correntes lida de um modo diferente com o mundo empírico, com a existência ou construção da matemática e com o que pode ou não ser chamado de matemática - justamente pelos aspectos anteriores. Estas correntes, mais ligadas à prática acadêmica dos matemáticos, também se fazem presentes no ensino de Matemática, mesmo que de forma mais branda.

Neste contexto, como tem sido pensado essa relação entre "a matemática" e o "mundo real"? Certamente há inúmeras respostas para esta questão, visto serem os professores e alunos de matemática os mais diversos, cada qual com suas práticas e seus "discursos" sobre a Matemática.

Numerosamente referenciado nas pesquisas do campo da Educação Matemática, Duval (2012), com Registros de representação semiótica e funcionamento cognitivo do pensamento $^{5}$, se baseia nas ideias da semiótica e destaca a importância nas mudanças de registro no aprendizado da Matemática. Seu texto inicia com as seguintes frases:

Há uma palavra às vezes importante e marginal em matemática, é a palavra "representação". Ela é, na maioria das vezes, empregada sob a forma verbal "representar". Uma escrita, uma notação, um símbolo representam um objeto matemático: um número, uma função, um vetor... Do mesmo modo, os traçados e figuras representam objetos matemáticos: um segmento, um ponto, um círculo. Isto quer dizer que os objetos matemáticos não devem ser jamais confundidos com a representação que se faz dele. (DUVAL, 2012, p.268, negrito nosso).

Como um exercício de pensamento, poderíamos imaginar Magritte parafraseando Duval: "Isto quer dizer que os objetos reais (como o cachimbo) não devem ser jamais confundidos com a representação que se faz dele", ou ainda, poderíamos pensar em Duval "parafraseando" Magritte:

${ }^{5}$ Somente no Google Acadêmico são contabilizadas 342 citações a este artigo. 


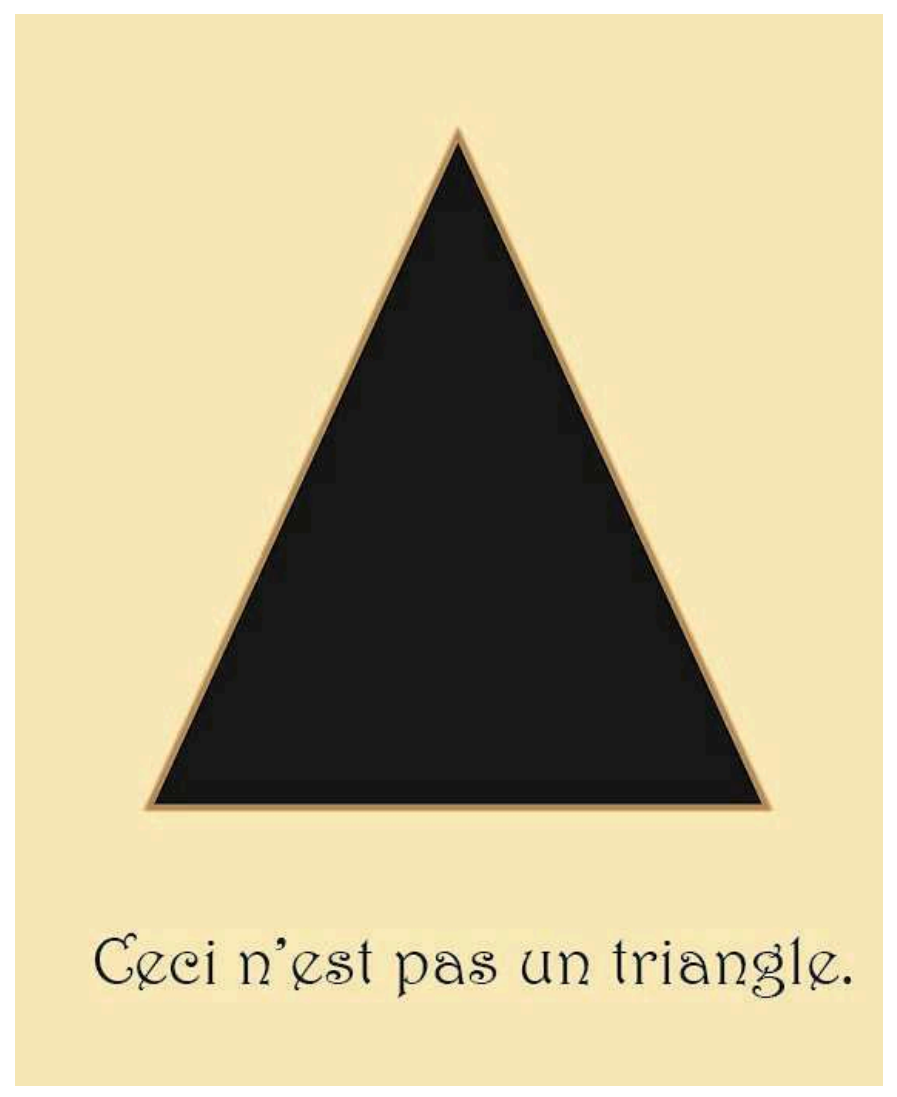

Figura 02: Ceci n'est pas um triangle

Fonte: criação para este texto

O próprio texto de Duval traz uma questão bastante pertinente à nossa discussão: “Como os sujeitos em aprendizagem poderiam não confundir os objetos matemáticos com as suas representações semióticas, se eles podem tratar apenas com as representações semióticas?” (DUVAL, 2012, p.268). Para além desta, poderíamos colocar outra: 'onde se encontram, então, os objetos matemáticos?'. Essa pergunta é análoga a 'qual a natureza do objeto matemático?'. O que nos levaria outra vez ao texto de Davis e Hersh e às várias filosofias da matemática.

Para Duval, e tantos outros matemáticos, e porque não dizer, tantos professores de Matemática, o objeto matemático está no "mundo das ideias", trata-se de objetos ideais inalcançáveis, só disponíveis a nós por meio de suas representações em nosso "mundo físico":

A impossibilidade de um acesso direto aos objetos matemáticos, fora de toda representação semiótica, torna a confusão quase inevitável. E, de modo inverso, como os sujeitos podem adquirir o domínio de tratamentos matemáticos, necessariamente ligados às representações semióticas, se eles não têm uma apreensão conceitual dos objetos representados? Este paradoxo é tão mais forte quando se identifica atividade matemática e atividade conceitual, e que se considera as representações semióticas como secundárias ou extrínsecas. (DUVAL, 2012, p. 268-269)

\footnotetext{
${ }^{6}$ Para o autor, um modo de solucionar esta questão é trabalhar com as diversas representações de um mesmo objeto.
} 
Se nunca teremos acesso aos objetos matemáticos, se eles são "de outro mundo", como se dá a produção destas representações e no que elas nos auxiliam? O conhecimento 'real', verdadeiro, "de outro mundo" seria então mais "verdadeiro" que nossas palavras e anotações "deste mundo"?

Outra possibilidade, seria dizer que a matemática não está em outro mundo, mas que se trata de convenções sociais bem estabelecidas, ideias que nos ficam para além do que dizemos dela: conceitos extraídos da essência das coisas. Para estes, parece ser possível desenhar um "ponto" em uma parede, dizer que é adimensional, uma localização no plano ou no espaço e, de alguma forma, abstrairmos daí uma ideia (única), a essência do que é o ponto da Matemática, mesmo ele sendo um ente primitivo (não definível).

O comentário acima me remete imediatamente a alguns comentários do filósofo Ludwig Wittgenstein quando fala sobre as cores, há inclusive uma obra toda dedicada a esta temática (WITTGENSTEIN, 2009b). Como aprendemos ou podemos aprender a essência das coisas, de uma cadeira, uma ferramenta ou de uma cor? Poderíamos mostrar a uma pessoa várias coisas azuis e dizer: "veja, o que elas têm em comum é o azul!", mesmo sendo uma azul claro, outra azul turquesa, azul da Prússia etc.? Tomando para nosso campo de atuação, reescreveríamos a pergunta: posso mostrar a alguém várias representações de pontos, retas e dizer "veja, o que eles têm em comum é o ponto, a reta etc.".

A ideia de cor, de uma cor pura, sua essência, visto tantas variações de uma paleta de cores nos parece algo "inalcançável”, para não dizer impossível. Uma rápida consulta a um software de edição de imagens nos disponibiliza uma infinidade de azuis, escolhendo apenas uma matiz, temos o seguinte quadro:

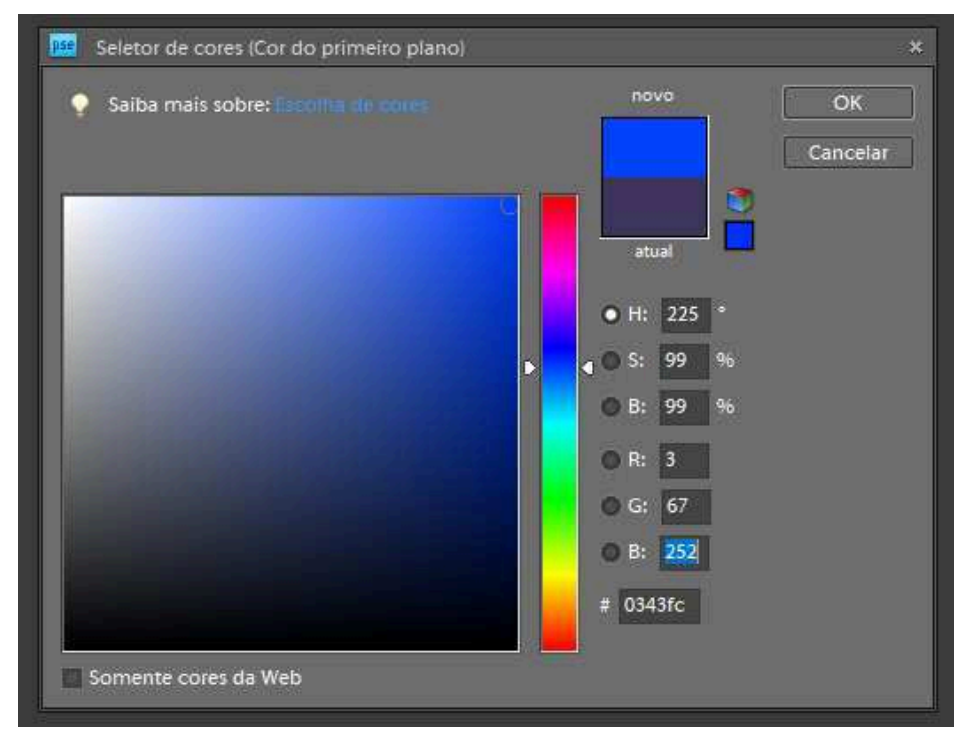

Figura 03: Paleta de cores do Adobe Photoshop Elements 8.0

Fonte: captura de tela.

O quadrado da esquerda nesta figura nos mostra as opções que temos apenas com esta matiz, que pode ser mudada na coluna ao centro da figura, veja que nesta coluna há outra 
infinidade de matizes que chamaríamos de "azuis". Ainda olhando para o quadro, como delimitaríamos onde acaba o azul e começa o branco ou o preto? $\mathrm{Na}$ borda da esquerda, seriam azuis esbranquiçados, acinzentados ou enegrecidos? Ou seriam um branco azulado, um cinza azulado e um preto azulado? As mesmas observações valem para a coluna central. Este software nos permite alterar 3 parâmetros $^{7}$ de 0 a 252 (253 opções para cada!), o que nos dá aproximadamente 16 milhões de "cores" diferentes para escolhermos, de alguma forma as dividimos em nossas falas em: amarelos, azuis, vermelhos, marrons etc. Seria possível escolher entre esta gigantesca paleta (invejável a qualquer pintor) aquele que é mais amarelo? Aquele que representa a essência do amarelo ou que é o próprio amarelo puro? Por qual motivo diríamos que a terna $(3,67,252)$ é (ou não) o azul puro?

Para Wittgenstein essa busca é vã. Não há nada "por trás" das palavras (fora do jogo de linguagem) ao que elas se relacionem ou estejam, de alguma forma, essencialmente ligadas e assim justifiquem a assertiva. Quando em um jogo qualquer grito "azul”, seja para diferenciar um objeto de outros, seja porque esta é a "palavra senha" para outra ação no jogo, não há algo estanque no "mundo das ideias" de onde eu pensei relacionar esta fala e quero que meus companheiros de jogo também relacionem a ela. "Azul” em um jogo qualquer pode ser uma "jogada completa" ou fazer parte de uma jogada. Poderíamos imaginar uma simples e cotidiana pergunta: "como vai você?”, seguida da resposta: "Tudo azul!" (como na música "sem pecado e sem juízo" de Baby do Brasil, 1985). Estaria este estado de espírito relacionado de alguma forma à cor azul nesta frase neste jogo? Caso sim, como poderíamos explicar "a mesma" resposta na cultura norte americana onde o "blue" (ou o blues) é justamente associado à tristeza? Como em "Linger on your pale blue eyes" (THE VELVET UNDERGROUND, 1969), ou, mais diretamente, em "When I'm feeling blue" (TRAVIS, 1997).

Poderíamos dizer que para Wittgenstein, na perspectiva de sua segunda fase, toda palavra é polissêmica. Conforme se muda o jogo, se muda a função de cada palavra, de cada frase no jogo, se muda o uso! O azul (ou blue) destas músicas em nada está relacionado à terna $(3,67,252)$ do software de edição de imagens, são jogos diferentes.

Ele nos exemplifica alguns desses jogos:

Comandar, e agir segundo comandos - Descrever um objeto conforme a aparência ou conforme medidas - Produzir um objeto segundo uma descrição (desenho) Relatar um acontecimento - Expor uma hipótese e prová-la - [...] Representar teatro - Cantar uma cantiga de roda - Resolver enigmas... (WITTGENSTEIN, 1999, § 23).

\footnotetext{
${ }^{7}$ Neste software há diferentes modos de geração das cores: o CMYK (Ciano, Magenta, Yellow e Preto) e o RGB (Red, Green e Blue), cada um dos sistemas gera toda sua paleta de cores a partir destas "cores base". Cada modo simula a interação de cores de formas diferentes, o primeiro trabalha com "cores impressas" o segundo com "luzes projetadas", estas ferramentas certamente nutririam em muito a discussão de Wittgenstein.
} 
Quando vemos dois pedreiros trabalhando e um grita para o outro: "pedra!"8, "água!" e seu ajudante reage adequadamente (conforme se esperava), poderíamos imaginar que a pessoa que recebe a ordem (palavra dita de certa forma) "acessa" uma informação, uma ideia essencial de "pedra", “água” e mesmo sem ser diretamente solicitado (só se falou "pedra!”), busca ao seu redor coisas que poderiam "caber" nestas categorias e, também sem ser solicitado, pega uma quantidade deste elemento e leva ao pedreiro que gritou tal nome. Outra possibilidade é pensar que ali naquele jogo essa "palavra solta" funciona como uma frase completa, ela designa perfeitamente a ação que se pretende e o que reforça esse ponto é que a ação é, de fato, realizada. Não se trata, como em outros modelos de comunicação, pensar que emissor elabora uma mensagem e a transmite por via verbal sonoramente e que receptor decodifica esta mensagem e depois age, não! Este falar e este fazer são jogadas deste jogo e quando o esperado pelos jogadores ocorre, temos o indicativo que funcionou, que ambos os jogadores entendem as regras deste jogo. Quando não funciona de imediato, os jogadores acrescentam elementos, palavras para essas jogadas (réplicas e tréplicas), podendo, inclusive, não estarem no mesmo jogo, ou seja, não procederem como se espera.

Poderíamos imaginar uma cena onde uma pessoa no canto da mesa gesticula em direção ao sal enquanto fala sobre seu dia e outra, sem nada ouvir a este respeito, pega o saleiro e entrega ao primeiro. Como poderíamos pensar esta cena em um modelo de representação semiótica, ou em um modelo de comunicação? Teria o primeiro pensado "quero sal - cloreto de sódio - $\mathrm{NaCl}$, aquilo que utilizamos para salgar a comida, um composto que em água se dissocia num cátion diferente de $\mathrm{H}+$ e um ânion diferente de $\mathrm{OH}$ - [1]. Eles são tipicamente o produto de uma reação química entre: uma base e um ácido." , e "mas como estou falando sobre outro assunto e não quero interromper a fala, vou então apontar para o saleiro com o dedo indicador, codificando esta mensagem por meio de sinais" e seu companheiro, ao receber a mensagem por meio de um canal visual, dissipa os ruídos e decodifica: "bom, ele apontou para o lado de cá, acredito que queria o saleiro, visto que a comida está um pouco sem sal" e, então, pensa: "vou esticar o braço, pegar o saleiro com esta mão e vou entregar a ele" e somente então: age $?^{10}$ Acreditamos que não!

Somos levados, a partir de Wittgenstein, a entender cada ação dessas como um lance no jogo, um lance completo, que não necessita de alguma justificação que esteja fora do jogo, aprendemos pelo uso, repetição (ou mesmo explicação em alguns casos) como se joga, aprendemos a apontar as coisas e as pessoas que estão próximas pegarem - em alguns jogos

\footnotetext{
${ }^{8}$ Fazemos aqui uma problematização a partir do parágrafo 2 da obra Investigações Filosóficas (Wittgenstein, $1999, \S 2)$.

${ }^{9}$ Definição de "sal” da Wikipédia, disponível em < https://pt.wikipedia.org/wiki/Sal>.

${ }^{10}$ Este modelo poderia ser chamado de uma concepção "mentalista" da linguagem, que separa corpo e mente.
} 
isso funciona, em outros, a regra é outra! Não faz sentido aqui distinguir linguagem/signo de referente/significado.

Poderíamos imaginar ou elencar vários jogos onde a "figuração", o "signo", a representação assume um papel que ultrapassa o de um desenho ou palavra - se assim quiséssemos dividir o mundo. Imaginemos um controlador de voos que observa um ponto luminoso na tela:

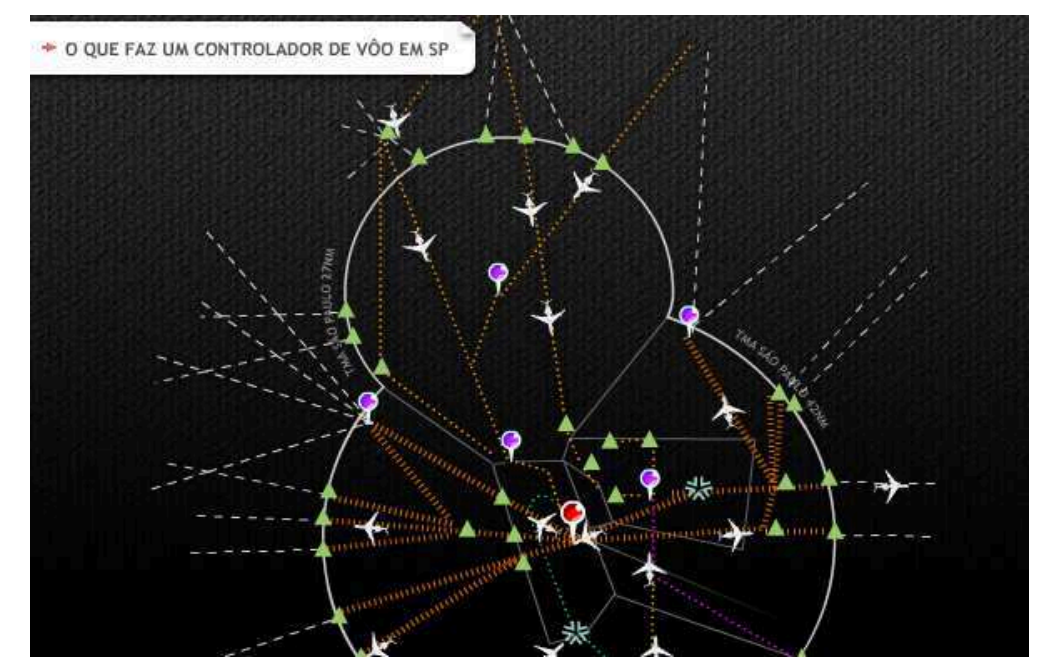

Figura 04: controle de tráfego aéreo

Fonte: http://g1.globo.com/Noticias/0,,IIF1103-5605-676,00.html

Imaginemos que para este controlador cada um desses pontos, figuras, não é um avião, voando a tal velocidade (normalmente de 500 a $1000 \mathrm{~km} / \mathrm{h}$ ) cheio de pessoas? Imagine que ele tome decisões baseados em uma ideia de "figura", de "imagem" meramente, afinal "Ce n'est pas un avion!", onde as figuras pudessem passar umas pelas outras, se interceptarem e continuaria tudo bem, como em uma aula de Desenho Geométrico. Certamente, teríamos sérios problemas. Podemos imaginar que nesta situação cada ponto tem que ficar longe do outro, há que se verificar altitudes (dos pontos?!), desenhar e prever suas trajetórias e rumos, neste jogo, cada ponto não é nem "o próprio" avião e nem um "signo", é uma peça em jogo que obedece determinadas regras (normativas) como em um xadrez e que coloca a responsabilidade de muitas vidas em suas mãos.

Quando conversamos com familiares sobre algum ente querido que "já se foi”, aquela palavra (nome) não é um signo que se liga “a aquele que já não está mais entre nós”, ou aos seus "restos mortais" ou a "uma alma no céu ou na terra", assim por diante. Independente da crença que temos sobre a morte, neste momento, aquele nome torna-se também um lance no jogo, um lance que nos põe a falar de "saudade", de "sentir falta", narrar episódios felizes ou tristes que passamos juntos etc. A quem, no mundo empírico, se ligaria um nome de alguém que já faleceu?

Wittgenstein nos propõe analogia semelhante utilizando o nome "Moisés" e questionando a possibilidade de atribuição de um significado único para este nome: 
79. Olhe com atenção o seguinte exemplo: Quando se diz "Moisés não existiu", isto pode significar diversas coisas. Pode significar: Os israelitas não tiveram um guia quando saíram do Egito - ou: seu guia não se chamava Moisés - ou: não houve um homem que tivesse realizado tudo o que a Bíblia narra a respeito de Moisés - ou etc., etc. - Segundo Russell, podemos dizer: o nome "Moisés" pode ser definido por meio de diferentes descrições. Como, p. ex.: "O homem que conduziu os israelitas através do deserto", "o homem que viveu neste tempo e neste lugar e a quem, naquela época, chamavam 'Moisés', que em criança foi retirado do Nilo pela filha do Faraó", etc. E, dependendo da definição que aceitamos, a proposição "Moisés existiu" adquire um outro sentido, assim como qualquer outra proposição que trate de Moisés. - E se nos dizem "N não existiu", questionamos também: "O que você tem em mente? Quer dizer que..., ou que ..., etc.?" Mas quando eu faço uma afirmação sobre Moisés,-estou sempre disposto a substituir qualquer uma dessas descrições por "Moisés"? Direi talvez: Por "Moisés" entendo o homem que fez aquilo que a Bíblia narra sobre Moisés, ou mesmo muitas dessas coisas narradas. Mas, quantas? Decidi quantas têm que se mostrar falsas para que eu desista de minha proposição como falsa? Tem o nome "Moisés" para mim, portanto, um uso fixo e claramente determinado em todos os casos possíveis?-Não é assim que eu, por assim dizer, tenho à disposição uma série de apoios e estou disposto a apoiar-me em um deles, caso os outros venham a ser tirados de mim, ou vice-versa? (WITTGENSTEIN, 2009a, §79).

Outro exemplo bastante rico e corriqueiro em nossos cotidianos é a frase: "Como o amor é lindo!' Se tentássemos atrelar estas palavras ao mundo empírico de forma ostensiva (como propôs Agostinho e discutido por Wittgenstein no IF, 2009a), ao que ligaríamos "como", “o", "amor", "é” e "lindo", separadamente? Esta ação também nos parece impossível! Pelo contrário, nos parece mais "razoável" entender essa frase como um lance de um jogo, por exemplo, quando alguém vê um jovem casal se beijando às sete horas da manhã antes de iniciar a aula (situação vivenciada hoje cedo, aliás!) e comenta com quem está ao lado: “Como o amor é lindo!". Isto não quer dizer, de forma alguma, que esta pessoa entende o conceito de "amor", de "lindo", de "como" e de "ser" e acredita que naquela situação estas definições se juntariam como tradução de uma ideia ali presente. Pode, muito pelo contrário, ser um lance de ironia, como quem diz "a essa hora da manhã?!". Note que isso também não quer dizer que este era o desejo de "dizer" dessa pessoa, como quem pensou isso, mas disse aquilo, não! O lance é completo, não faz sentido pensar na distinção de referente e referencial.

Este modo de compreender a linguagem nos traz implicações diretas para o ensino (de matemáticas) e para a pesquisa (no campo da Educação Matemática). Não tomar a linguagem como referencial, ou seja, na qual ela se refere a algo do mundo empírico ou ideal (mental) joga por terra a possibilidade de materializar o mundo por meio de textos. Os textos e linguagens são intrinsicamente parte do mundo, constituintes do mundo como os conhecemos. Para nós não faz sentido colocarmos de lado o mundo e de outro a linguagem, que poderia explicá-lo, fundamentá-lo, ou qualquer outra ação sobre este, ela é também o mundo, a realidade. 
Quando nos colocamos a explicar alguma coisa, especialmente se tentamos ser didáticos, ou praticar uma transposição didática ${ }^{11}$, nos colocamos em um novo jogo, não no jogo do fazer tal coisa, mas no jogo do explicar, do falar ou escrever sobre, que é outro Wittgenstein nos alerta para a impossibilidade da tradução. Dizer jogar um jogo, não é jogálo! Traremos aqui dois pontos de implicações: para a sala de aula de Matemática e para as pesquisas do campo da Educação Matemática.

\section{Para a sala de aula de Matemática}

Neste ambiente, destacaríamos a multiplicidade de jogos de linguagem que chamamos de matemática, o aspecto normativo do jogo de linguagem da matemática acadêmica e sua "nenhuma" validação pelo mundo empírico. Levando em consideração o pensamento wittgensteiniano, qualquer explicação de um fenômeno é um jogo diferente e, normalmente, especialmente na matemática, normativo. Mas o que isso quer dizer? No caso da matemática, se efetuamos uma conta (que nunca fizemos antes com aqueles números, por exemplo) seguindo certo algoritmo aprendido por nós, chegamos a um determinado resultado, como saber se o resultado está correto? Poderíamos juntar objetos de forma a simular tal operação e ver se o resultado obtido com o cálculo é o mesmo obtido na operação com os objetos; podemos pegar uma calculadora e realizar o mesmo cálculo e ver se o resultado é o mesmo ou; podemos retomar o algoritmo e observarmos em nossas anotações se o seguimos corretamente, se não deixamos de fazer alguma coisa que ele previa. Imagine que a operação desejada era: $\frac{\mathbf{6}}{\mathbf{4 5}} \div \frac{\mathbf{2}}{\mathbf{5}}$, como verificar no mundo empírico tal resultado? E na calculadora? A terceira opção nos parece a mais provável em um ambiente escolar e o que ela nos diz? Retomamos o algoritmo e vemos se o seguimos corretamente, ou seja, vemos se seguimos a norma estabelecida a se seguir nestas situações: vejo se inverti corretamente a segunda fração, vejo se multipliquei corretamente numeradores e denominadores etc. e aqui novamente o recurso à norma, se por ventura tenho dúvidas se multipliquei corretamente o 45 por 2, verifico no mundo empírico esta multiplicação (precisando aqui de 90 objetos iguais) ou recorro a alguma outra norma da matemática como a tabuada (decorada ou multiplicada nos dedos da mão)? Analogamente, Wittgenstein vai recorrer diversas vezes ao jogo de xadrez e aqui perguntaríamos: por que o cavalo anda "em L"? Há alguma relação com o movimento do animal ou é assim para satisfazer uma exigência do próprio jogo (que é uma prática social constituída historicamente)? Pensando no cálculo feito acima, se tenho dúvidas

\footnotetext{
${ }^{11}$ Chevallard (2013, p.9) define: "Ensinar um corpo de conhecimento é, portanto, uma tarefa altamente artificial. A transição do conhecimento considerado como uma ferramenta a ser posto em prática, para o conhecimento como algo a ser ensinado e aprendido, é precisamente o que eu tenho chamado de transposição didática do conhecimento."
} 
se procedi corretamente o movimento da peça cavalo no jogo, poderia recorrer ao movimento do animal para saber se procedi corretamente? Para nós essa resposta é não.

Perguntaríamos aqui: o zero é um número natural? Os mais diversos livros de cálculo dirão que sim! No entanto, toda Teoria dos Números dirá que não ou o excluirá de seu conjunto de trabalho, pois ali não é conveniente adotar o zero como parte do conjunto, imagine o que seria do m.m.c. (mínimo múltiplo comum), sendo o zero parte do conjunto, ele é também múltiplo de todos os outros números e é o menor deles, todo m.m.c. seria o próprio zero, isso sem falarmos dos divisores, que resposta daríamos à pergunta: $n$ é divisível por zero? E se n também for zero? Na perspectiva aqui adotada, não buscamos tal desambiguação, mas compreender estes diferentes jogos (estas diferentes práticas sociais ${ }^{12}$ ) de matemática (a Teoria dos Números e, por exemplo, o Cálculo Diferencial Integral ou a Aritmética das primeiras séries) e evidenciar suas regras.

A matemática escolar e também a acadêmica (para não entrar aqui em outras tantas possíveis adjetivações - C.f. VILELA, 2007), cada qual com suas especificidades, são jogos como o xadrez, são normativos, criam regras para satisfazer suas próprias jogadas. Um bom exemplo desta normatividade é a Geometria Euclidiana Plana como geralmente ensinada nos cursos de formação de professores: um sistema axiomático que se propõe perfeito, como um castelo de cartas: se retirarmos um elemento da base (um postulado, teorema ou definição) derrubamos todo o castelo. As retas paralelas, por exemplo, se definem apenas por não terem algum elemento (ponto) em comum e as propriedades de manterem sempre a mesma distância uma da outra (recurso comumente utilizado nas escolas de Educação Básica para falar de paralelas) ou possuírem o mesmo coeficiente angular (recurso utilizado no Ensino Médio no estudo da Geometria Analítica), são apenas resultados, consequências (o que para um jogo é uma definição, para outro é apenas consequência). Estariam as retas paralelas ancoradas de alguma forma no mundo empírico? Ou seriam estas afirmações apenas representações de uma ideia de retas paralelas ideais que residiriam em algum outro lugar (mundo)?

Para nós são jogos, que assim se estabelecem para atender as demandas que vão sendo construídas coletivamente ao longo da história. Não se trata, salientamos, de meros acordos coletivos pontuais, mas de processos muitas vezes lentos e diretamente relacionados aos conhecimentos, metas, sociedades e jogos já disponíveis naquele momento histórico e que estavam disponíveis àqueles grupos que desenvolveram tais ideias. Ainda na Geometria Euclidiana Plana, se tomarmos a ideia de infinito presente nos Elementos de Euclides (infinito

\footnotetext{
${ }^{12}$ Salientamos que Wittgenstein não utiliza a expressão "práticas sociais", mas ela parece ser uma analogia interessante (ainda que com limitações) para os jogos de linguagem se pensarmos nela como sendo praticada por um grupo, com regras próprias que são constantemente e historicamente elaboradas e que variam de grupo para grupo e não carregam traços essenciais. Wittgenstein defende que a linguagem ocorre como os jogos, são múltiplos, diversos e, ainda assim, carregam semelhanças de um para o outro e deste com um terceiro. São desta forma não uma linguagem, mas jogos de linguagem, ligados por semelhanças como as de família.
} 
potencial) e as noções de infinito presentes em um manual qualquer dos nossos cursos de licenciatura (infinito potencial e infinito atual), elas são muito divergentes e os incrementos atuais a essa geometria emprestam muito do Cálculo Diferencial e Integral (Análise), só possível como o conhecemos depois de Newton e Leibniz.

Com isso, relativizamos sobremaneira a frase de Galileu. Entendemos que há um jogo em que sua frase se insere, como há um onde o nosso discurso também se insere (formas de vida diferentes). É possível dizer que a matemática está em todo lugar? Certamente, há um jogo de linguagem, muito popular nas salas de aula que o aceita. No entanto, nós diríamos que é possível "ver" a matemática em todo lugar, e muitos veem essa matemática, outros tantos, e diríamos em maior número, não a veem, pois ela não está ali para eles - e estes não estão errados ou possuem um conhecimento inferior. São determinados jogos que colocam a matemática em todo lugar.

Admitindo a(s) matemática(s) como jogos, faz se necessário entender melhor estes jogos e as interfaces (semelhanças de família) que eles têm com outros jogos, de dentro e de fora da escola. Este posicionamento relativiza visões dogmáticas sobre o conhecimento científico, ao adquirir tal conhecimento não se está a ascender na escada do conhecimento, a ficar mais próximo da verdade (o Real platônico), está somente a aprender outro jogo. A matemática, como qualquer jogo, é tanto ficção quanto realidade, pois a ficção é um elemento da nossa vida, das nossas práticas cotidianas; e o que chamamos de realidade advém de um processo criativo que se situa na linguagem e variável conforme a situação e contexto, portanto: produzido! E o que é a ficção se não uma produção criativa a partir da realidade? Desta forma, não faz sentido buscarmos uma distinção entre ficção e realidade, nem mesmo um contínuo, pois não conseguiríamos delimitar estes extremos. A matemática se constitui assim um jogo tão real quanto ficcional.

\section{Para o campo da Educação Matemática}

No que se refere às pesquisas, alguns trabalhos nossos já se debruçaram sobre um modo de fazer inspirado na filosofia de Wittgenstein, poderíamos indicar, especificamente apostando em uma estética ficcional: Pinto (2013), Silva (2016) e Morais (2017).

$\mathrm{O}$ ato de pesquisar, via de regra, implica em exercitar alguma prática junto a alguma comunidade ou acervo e, posteriormente ou simultaneamente, elaborar um texto que traduza aquele momento inicial, recheado de referenciais que não vivenciaram tais ações, mas que nos ajudam a explicá-la e traçar conclusões. Neste momento, duas questões podem ser colocadas: é possível explicar um acontecido? É possível ser fiel àquele momento vivenciado junto a uma comunidade ou acervo? 
Wittgenstein questiona a filosofia que não leva em conta os usos ordinários das palavras e, pelo contrário, tenta dar a elas uma conotação metafísica, buscando essências, significados que não residem entre nós e em nossas práticas: a filosofia deixa tudo como está! Quando teorizamos sobre algo e atribuímos novas palavras para determinadas ações ocorridas, ou recolocamos palavras velhas com um novo sentido explicativo em nosso texto, estamos novamente, como já advertiu Wittgenstein, produzindo problemas filosóficos, retirando as palavras de seus usos ordinários para buscarmos uma verdade que não reside em nossas práticas: mal entendidos. Sua proposta é que não expliquemos o mundo, mas vê-lo! Hebeche (2003) em um texto já bastante conhecido por aqueles que trabalham com as ideias de Wittgenstein intitula: “não pense, veja!”, não há nada para se descobrir no mundo, os jogos não devem ser explicados, mas sim jogados!

Como podemos ensinar alguém a jogar bola? Certamente um livro sobre o tema tocaria pontos importantes do jogo, mas pouco faria para que o jogador passasse a cobrar melhor um escanteio. Isso não tira do jogo a linguagem, mas temos que ver que tomamos aqui a linguagem em sentido amplo: os jogadores, juízes, bandeirinhas e torcida, participam deste jogo de linguagem, mas também é linguagem "o peso da camisa”, "uma série de vitórias consecutivas do time adversário", "o décimo segundo jogador" e uma série de outras questões que estão na linguagem, mas não no texto escrito. Nós, aqui, ao escrever sobre estas questões não estamos a jogá-las, mas em outro jogo: “o jogo de escrever sobre tais coisas”. Há semelhanças, potencialidades nisso? Certamente que sim, mas é importante ressaltar: semelhanças e potencialidades - nada além disso! Nenhum método "supostamente científico" de observação e descrição do fenômeno, como poderiam querer os mais positivistas, vai nos garantir essa apreensão da "verdade do fato" (como alguns gostariam). Frisamos novamente, estamos aqui - enquanto pesquisadores - fazendo outra coisa, jogando um novo jogo e, sabendo disso, qual enfoque daremos aos nossos trabalhos? Esmeraremos nos na busca (inalcançável) de aproximar nosso texto "da verdade ocorrida de fato" quando praticávamos tais ações (entrevista, questionário, aplicação de oficinas, aulas, cursos etc.) ou apostaremos nas potencialidades de nossos textos?

Nós temos optado pela última opção. Quais efeitos o material que estamos produzindo pode causar em nosso leitor? Que questões podem ser colocadas a ele de forma que este também se questione, também se incomode e se mova em relação à temática que estamos discutindo/pesquisando? Seria a estrutura tradicional de textos acadêmicos (com pretensões de ser hermética, higienizada e impessoal) a melhor forma de pensar nestes efeitos e de conduzir nosso leitor por novos caminhos? Todas estas questões não nos impedem de trazermos entrevistas, acervos, excertos de outros textos, mas nos coloca a mobilizá-los de forma diferente. 
Em Pinto (2013), investigávamos o Projeto Minerva (PMi), uma ação em nível nacional e que perdurou por mais de 10 anos. Entrevistamos um casal de alunos do interior do Rio de Janeiro que cursou o Primeiro Grau pelo Minerva, um monitor do interior do Mato Grosso do Sul, que atuava na zona rural alfabetizando adultos pelo Projeto, um professor que escreveu o material que viraria, sem que ele soubesse, a "apostila" (Fascículo) do Projeto de Segundo Grau e uma das produtoras que esteve à frente do Projeto, junto a um redator que roteirizou justamente as aulas de Matemática. Além destes depoimentos, a SOARMEC disponibiliza em seu site uma diversidade de entrevistas com importantes personagens da história da Rádio MEC (que produzia e veiculava o PMi), estas também nos serviram de acervo (MIGUEL, 2015, nos fala sobre arquivo cultural de partida.). Surgiram daí uma diversidade de pontos de vista, muitas vezes disjuntos, pareciam falar de coisas diferente e, pelo que entendemos, falavam. Junto desta multiplicidade de narrativas a respeito do PMi, estudávamos também um grande dificultador do projeto: como ensinar matemática (uma disciplina tipicamente visual) pelo rádio? Colocamo-nos a estudar também a linguagem radiofonia e os modos de se produzir um texto para o rádio - há um jogo de linguagem próprio para isso: bordões, repetições, frases curtas, sonoplastia etc. (Pinto \& Garnica, 2014). Munidos de todo este estudo e acervo, produzimos um debate radiofônico que tenta, até uma parte do texto, convencer nosso leitor que se trata de uma transcrição de duas fitas k-7 encontradas por mim no acervo de uma rádio, um debate de dois dias, de um programa chamado "A Voz do Povo" que tem como locutor Elias Júnior, um dos personagens criados por nós para este debate. Elias, bem como os demais, não são cópias de nossos depoentes, mas são criados junto e a partir deles, junto e a partir dos documentos que encontramos, junto e a partir das vivências ao longo da pesquisa, em uma simbiose, advinda de um processo antropofágico, onde nos alimentamos de tudo isso e nos colocamos a produzir junto e a partir deles, sem delimitações do que vem de onde, ou preocupações se todos estão "bem representados ali”. Por outro lado, inúmeras preocupações novas surgiram, como o respeito à estética do rádio, à temporalidade em que ocorria o debate (década de 1990), à estética de uma transcrição (contendo marcas e vícios da oralidade), à coerência "interna" dos personagens ao longo do programa, à criação de personagens "esféricos", com histórias, vivências, com nomes, sobrenomes e datas de nascimento. Convencer nosso leitor que se tratava efetivamente de um debate transcrito não foi tarefa fácil, foram inúmeras reescritas do material até a versão final. Além destes aspectos, utilizamos a ficção para atingir mais um objetivo: confrontar, na tentativa de problematização, os vários discursos sobre o Projeto Minerva que encontramos ao longo da pesquisa. O que a produtora do Rio de Janeiro diria ao ouvir o monitor que subvertia a proposta inicial do Projeto ao alfabetizar seus alunos e utilizar aquele momento como espaço de resistência à ditadura militar, trazendo para o encontro 
discussões políticas locais. O que este monitor diria a esta produtora ou ao professor que escreveu o material de Matemática? O casal do Rio de Janeiro, que teve no Projeto sua única formação escolar concordaria com o político de São Paulo que, em uma reunião da Assembleia Legislativa pedia o fim do Projeto Minerva?

Nosso debate ficcional propiciava não o encontro dessas pessoas - acreditamos que isso jamais vá ocorrer - mas o encontro de ideias que estavam presentes em suas falas, de posicionamentos que identificamos em seus depoimentos. Neste sentido, a riqueza propiciada pelo debate não poderia ser ultrapassada nem mesmo pelo encontro "real" desses depoentes, visto que este debate é PRODUÇÃO! Mescla falas, vivências, possibilidades de leituras advindas dos referenciais teóricos, estética do rádio, estética de transcrição de depoimentos, é uma outra coisa.

Da mesma forma, Silva (2016), que pesquisou sobre a formação de professores que atuavam em Paranaíba na segunda metade do século XX, compôs cenas sobre esta formação. Alguns trabalhos historiográficos tem apostado na palavra "cenários", a autora troca para "cenas" por acreditar que o aspecto do movimento dos personagens nesta formação era uma das marcas mais importantes que via. Nestas cenas ela propõe ao leitor uma viagem por uma grande avenida com diversas saídas, brincadeiras de criança como a gangorra e a ciranda, um paciente que recebe curativos entre outras. Nestas metáforas ela discute a influência da política no contexto escolar, a urgência e emergência dos cursos de formação de professores na região, os modos, sempre aquém do desejado, de realização destes cursos entre outros. Silva e Pinto (2017), ainda a partir do trabalho realizado ao longo de 2014 a 2016, elaboraram uma narrativa (que poderíamos chamar de ficcional) que conta a história de dois professores que viajam por uma balsa sobre a divisa de Mato Grosso do Sul e São Paulo, durante a viagem eles narram diversas histórias, seus medos, angústias e expectativas quanto ao trajeto, muito tortuoso, e quanto à formação, muito desejada e difícil de ser alcançada.

Já Morais (2017), ao estudar um curso de licenciatura em matemática na modalidade semipresencial da UFMS, elabora, em seu movimento analítico, um fórum de um ambiente virtual de aprendizagem onde participam personagens também criados por ela. A estética de um fórum desta natureza, a dificuldade da escrita para os alunos ao invés da fala, a desconexão entre postagens, que depois são novamente retomadas, o espaço temporal entre uma colocação e a resposta de um colega são elementos que a autora tentou trazer para seu exercício ficcional. Além disso, ela discutiu neste debate por meio destes personagens questões como as dificuldades enfrentadas por professores e alunos ao estarem em um curso EAD pela primeira vez, a falta de formação específica para esta atuação, a relação deste curso com anteriores, principalmente as licenciaturas parceladas, as dificuldades burocráticas e preconceitos enfrentados dentro da própria universidade. Novamente, a autora cria 
personagens que se posicionam frente a estas questões, inquirem um ao outro, fazem adendos nas falas dos colegas, enfim, problematizando as falas uns dos outros. Este movimento não busca cristalizar verdades, mas sim explicitar facetas, nuances e particularidades.

Desta forma, estes trabalhos tentam não dizer dos jogos jogados por seus entrevistados, mas jogá-los efetivamente. Tentam seguir as regras dos jogos nos quais os depoentes se inserem, mostrando o fazer e não o falar sobre. Neste sentido, estas análises não são explicativas, por mais que, ao lê-las, muito é possível de ser pensado, refletido e, de uma forma ampla, apreendido. Abre-se ao pesquisador a possibilidade de produção, criação, sem as amarras que tentam fixar o que é o real e o que é o fictício.

\section{Breves considerações}

Neste texto abordamos inicialmente alguns modos de conceber o mundo e a linguagem como coisas separadas, onde a segunda representa elementos da primeira. Abordamos também o modo como Wittgenstein contrapõe este pensamento dicotômico e essencialista, e algumas apropriações nossas sobre seu pensamento. Argumentamos aqui pela não separação entre estes dois "mundos" elencados acima, mas na produção simultânea de um e outro, de um pelo outro. Separar linguagem (representação) e mundo (representável) excluiria, inclusive, a linguagem como parte deste "mundo". Melhor pensarmos que nossas práticas cotidianas são constituídas e constituem o que vemos, sentimos e dizemos, são nossas formas de vida e jogos de linguagem, estamos em tudo isso sem possibilidade de afastamentos. Linguagem é parte constituinte do mundo, mundo real - se preferir -, e tomamos linguagem não só no seu aspecto verbal, mas em sentido amplo, com cheiros, gestos, olhares etc. é uma linguagem atrelada a um corpo que a manifesta e que a percebe, pensar linguagem sem corpo é se colocar em uma empreitada metafísica, da qual tentamos nos afastar.

[...] para Wittgenstein, o mundo do pensamento (ou da 'representação') não preexiste e nem subsiste fora ou independentemente dos jogos de linguagem, pensar só pode ser também uma encenação corporal da linguagem, isto é, a participação corporal em jogos de linguagem, na medida em que só podemos pensar com o nosso corpo. (MIGUEL, 2015, p. 263).

Este modo de entender a nossa constituição do mundo atrelada e indissociável da linguagem nos coloca em dois movimentos distintos para a sala de aula de Matemática e para as pesquisas, especialmente no campo da História da Educação Matemática.

Para a sala de aula, nos põe a pensar sobre a filosofia da matemática, sobre como entendemos a relação de matemática e mundo. Inspirados em Wittgenstein, diríamos: a matemática enquanto jogo é parte do mundo, não está fora dele, não o representa de alguma forma. Neste sentido, não há o que buscar fora da matemática para justificá-la, ela é em si um jogo completo, com suas regras normativas que determinam o que faz e o que não faz sentido 
ali, como deve ou não ser utilizada uma expressão ou símbolos. A matemática, tão ficcional e tão real quanto qualquer outra coisa, pode nos servir de inúmeras formas, como deleite, como prática social escolar, como possibilidade de se pensar outras coisas. No entanto, é importante salientar, a matemática escolar é apenas mais um jogo, um conjunto de jogos, e sua importância na sociedade e a escolha desta ou daquela para ser obrigatoriamente ensinada nas escolas precisa ser discutida. O estatuto de 'mãe' de todas as outras ciências cai por terra, bem como cai por terra ser ou não uma ciência, na escola ela é, antes de mais nada, conteúdo escolar e, muitas vezes, pouca ou nenhuma semelhança tem com atividades do cotidiano extraescolar dos alunos ou com a prática profissional do matemático. Tão pouco se deve acreditar que a matemática escolar seja uma transposição ou adequação destas outras duas, ela tem suas regras próprias e é preciso entendê-las, como destacou Vilela (2007) e Pinto (2009). Seria possível, inclusive, propor outras matemáticas para habitar o espaço escolar. Não encontramos, fora o desenvolvimento histórico, justificativas para muitos dos jogos que estão aí, postos na escola, de forma estanque, que não se justificam nem pelo desenvolvimento cognitivo (algumas práticas se fundamentam no decorar de fórmulas) nem na aplicação no cotidiano extraescolar (diversos conteúdos se fundam em si mesmos). Isso não significa que não sejam interessantes, seja para o deleite, seja pela prática de trabalhar com tais conteúdos, mas é necessário que se explicite seus motivos, para que suas escolhas estejam pautadas em critérios que respeitem, entre outras coisas, os anseios da comunidade escolar como um todo, ela deveria poder escolher quais jogos quer jogar e por quais motivos.

Ainda para a sala de aula este aspecto um tanto relativo do pensamento wittgensteiniano nos coloca a refletir sobre cada sala de aula, cada aluno traz para este ambiente outros jogos que participa fora da escola e que muitas vezes acredita que ainda sejam estas regras que estejam vigorando. É importante que o professor observe estes jogos e ajude seu aluno a jogar estes novos jogos, que têm regras novas, diferentes da que ele conhece (e as quais ele vai querer erroneamente replicar). Seria possível ao professor tentar entender minimamente os outros jogos que os alunos participam e tentar se aproveitar de algumas regras que estes alunos já conhecem para inserir um novo jogo? Acreditamos que sim, mesmo certos das dificuldades que isso traz para uma sala de muitos alunos.

Outra implicação para a sala de aula que envolve a distinção entre jogos diferentes neste espaço diz respeito à diferença fundamental entre o jogo de observar o professor explicar e o jogo de fazer um exercício ou uma atividade ${ }^{13}$. Muitos alunos podem ser peritos

\footnotetext{
${ }^{13}$ Cada jogo se joga com o corpo inteiro, não nos parece possível separar mente e corpo, sentar, observar e ouvir é muito distinto de pegar um lápis, ler um enunciado, elaborar e desenvolver estratégias escrevendo coisas. Estas separações, típicas do pensamento cartesiano estão presentes, por exemplo, na fala de Yves Chevallard: "A relação didática une três e não dois "objetos" a saber: o professor, o ensino e, por último, mas não menos importante, o conhecimento; ou, para ser ainda mais preciso, o conhecimento ensinado. Esta é uma definição mínima, que precisa de mais comentários." (2013, p.6).
} 
no primeiro e pouco habilidosos no segundo. Em outras palavras, um aluno pode ser capaz de entender perfeitamente a explicação de um professor e ser incapaz de, na sequência, realizar uma atividade envolvendo tais conceitos: são jogos diferentes, as regras que valem em um não valem no outro. Mais ainda, pouco se deve esperar que os alunos, por iniciativa e conhecimento próprios, "peguem" esses conteúdos da escola e os desenvolvam, no seu dia-adia fora da escola, aplicação para eles - são jogos muito diferentes! Caso anseie que os alunos façam isso, então é isso que se deve fazer dentro da escola.

Já para o campo de pesquisa, e mais diretamente ao campo da História da Educação Matemática (HEM), onde atuamos, temos outras implicações. Se não há como representar o mundo por meio da linguagem (a linguagem é parte constituinte do mundo como o conhecemos) não há aqui intenção de fidelidade ao "fato histórico" (PINTO, 2015). Não se busca, ao trabalhar com narrativas de depoentes, por exemplo, por acareações, identificar versões mais verdadeiras, cada uma se constitui como um jogo próprio de dizer tais e tais coisas. Propomos então o que estamos chamando aqui de uma historiografia (des)respeitosa ${ }^{14}$. Este título tenta ser provocativo, assinalando para uma postura também provocativa, ou, no mínimo, polêmica, que defendemos para os trabalhos historiográficos de forma geral e particularmente na História da Educação Matemática. Frente à impossibilidade de representação, apostamos na potencialidade daquele que lê, que analisa uma determinada temática. Propomos então análises desrespeitosas que não apenas "observem à distância", mas que toquem (não apenas tateiem!), apertem, sintam o cheiro e mastiguem, numa simbiose que agora não permita mais termos o pesquisador sem este estudo e tão pouco "acessarmos" este passado sem as marcas das mãos do pesquisador que a tocou. Esta obra de arte-passado tem agora um novo autor, aquele que recriou a obra por suas mãos. Para nós, isso sempre foi desta forma, no entanto, sem a admissão desse desrespeito, antes indesejável, excluído da escrita final dos relatos, agora assumido e desejável, a potência e o sentido de fazer pesquisa. Ao pesquisador que tem levantado/produzido seus dados, em geral e em grande escala, deixaria a pergunta: e agora, o que você pode fazer com isso?

\footnotetext{
${ }^{14}$ Em uma rápida busca pela palavra 'respeitar' na internet temos vários usos, dentre eles nossa negativa se opõe a: (...) 2. demonstrar acatamento ou obediência a; cumprir, observar. 3. ter medo de, recear. (...) 6. ter cuidado com; não perturbar. (...) 9. estar na direção; estar voltado; apontar. 10. guardar o decoro que convém à sua situação, à sua dignidade; dar-se ao respeito. (RESPEITAR - Dicionário Google). 


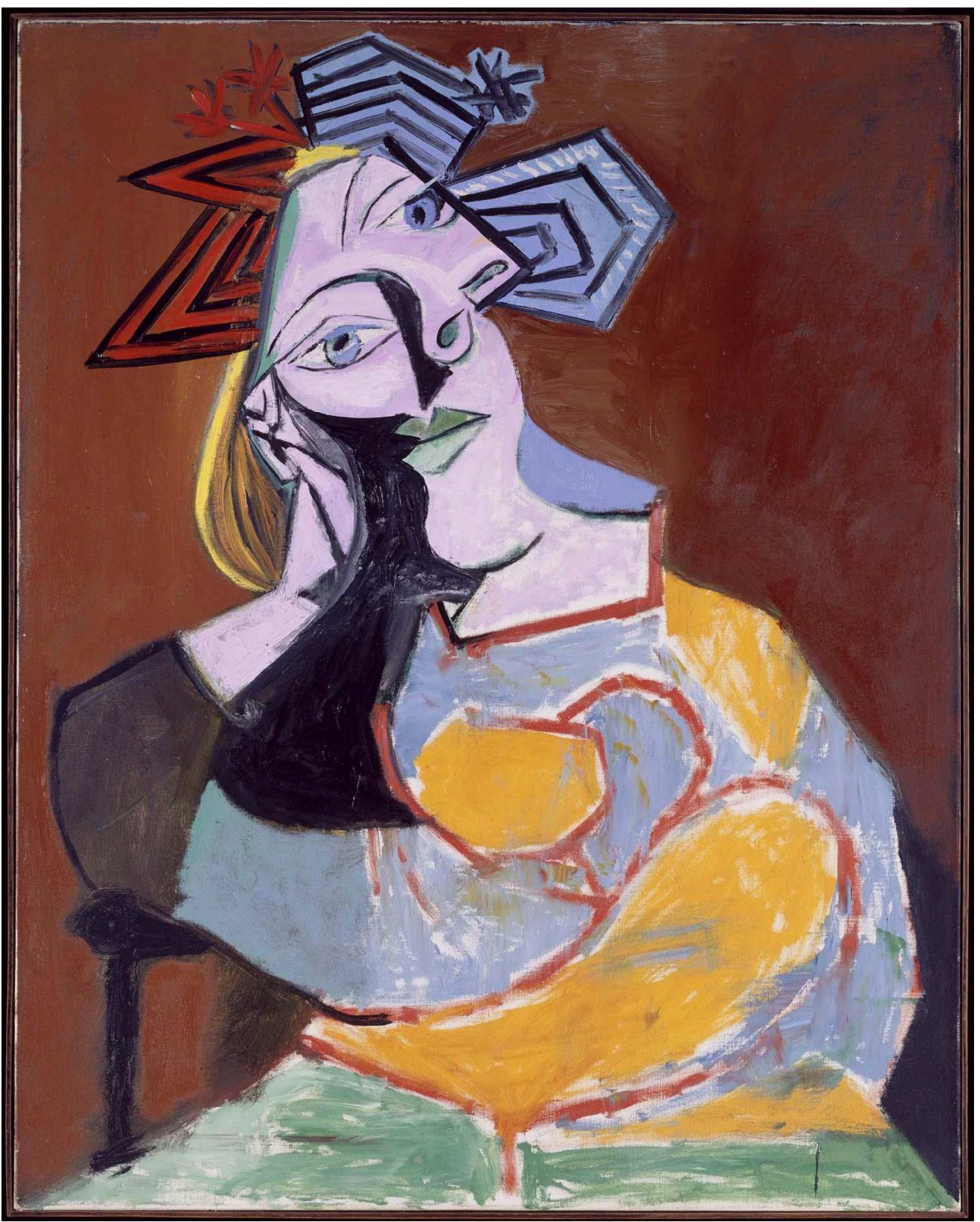

Figura 05: Mulher sentada apoiada sobre os cotovelos.

Fonte: Pablo Picasso (1939). Disponível na internet: < http://www.dionisioarte.com.br/nossas-10-obrasfavoritas-do-picasso/>

"Eu não pinto as coisas como as vejo, mas sim como as penso" (PICASSO, P.)

\section{Referências}

BABY DO BRASIL. Sem Pecado e Sem Juízo. In. Sem Pecado e Sem Juízo. Columbia Records, 1985.

BARKER, S. F. Filosofia da Matemática. Rio de Janeiro: Zahar, 1976.

CHEVALLARD, Y. Sobre a Teoria da Transposição Didática: algumas considerações introdutórias. Revista de Educação, Ciências e Matemática. v. 3 n. 2, p. 01-14, 2013.

DAVIS, P. J.; HERSH, R. A Experiência Matemática. Rio de Janeiro: Francisco Alves, 1985.

DUVAL, R. Registros de representação semiótica e funcionamento cognitivo do pensamento. Registres de représentation sémiotique et fonctionnement cognitif de la pensée. Revemat: Revista Eletrônica de Educação Matemática, Florianópolis, v. 7, n. 2, p. 266-297, 2012. 
Disponível em: <https://periodicos.ufsc.br/index.php/revemat/article/view/19811322.2012v7n2p266>. Último acesso em 01 de ago 2018.

FOUCAULT, P. M. Ceci n'est pas une pipe: Sur Magritte, Montpellier: 1973.

HEBECHE, L. A. Não pense, veja! Sobre a noção de semelhanças de família em Wittgenstein. Veritas (Porto Alegre), v. 48, p. 31-58, 2003.

MAGRITTE, R. Les Deux Mystères. gravura no papel, 180 x 130 mm. 1966. Disponível em: $<$ http://www.christies.com/lotfinder/Lot/rene-magritte-1898-1967-les-deux-mysteres5705498-details.aspx>. Último acesso em 01 de ago 2018.

MAGRITTE, RENE. La trahison des images. Óleo sobre tela, dimensões 63,5×93,98 cm. Museu de Arte do Condado de Los Angeles, 1929. Disponível em $<$ https://www.historiadasartes.com/sala-dos-professores/a-traicao-das-imagens-renemagritte/>. Último acesso em 01 de ago 2018.

MIGUEL, A. A Terapia Gramatical-Desconstrucionista como Atitude de Pesquisa (Historiográfica) em Educação (Matemática). Perspectivas da Educação Matemática, v. 8, Número Temático, p. 607-647, 2015.

PINTO, T. P. Linguagem e Educação Matemática: UM mapeamento de usos na sala de aula. Dissertação de Mestrado - Universidade Estadual Paulista (UNESP), Rio Claro, 2009.

PINTO, T. P. Projetos Minerva: caixa de jogos caleidoscópica. Tese de Doutorado em Educação para as Ciências - Universidade Estadual Paulista (UNESP), Bauru, 2013.

PINTO, T. P. Produção de Histórias sobre/na Educação Matemática: um exercício com os Projetos Minerva mobilizando um texto ficcional e Fotografias Compósitas. Perspectivas da Educação Matemática, v. 8, Número Temático, p. 862-881, 2015.

PINTO, T. P.; GARNICA, A. V. M. O Rádio e as Matemáticas: um estudo sobre o Projeto Minerva. Perspectivas da Educação Matemática, v. 7, n. 13, p.152-180, 2014.

MAGGIE, Y. Isto não é um cachimbo. Portal G1.2015. Disponível em: http://g1.globo.com/pop-arte/blog/yvonne-maggie/post/isto-nao-e-um-cachimbo.html>. Último acesso 01 ago. 2018.

MORAIS, A. C. L. de. Licenciatura em Matemática da UFMS: movimentos precursores e implantação de um curso a distância. Dissertação de Mestrado em Educação Matemática Universidade Federal de Mato Grosso do Sul, Campo Grande, 2017.

SILVA, N. C. da. Cenas sobre a formação e atuação de professores de Matemática de Paranaíba/MS na segunda metade do século XX. Dissertação de Mestrado em Educação Matemática - Universidade Federal de Mato Grosso do Sul, Campo Grande, 2016.

SILVA, N. C. da. PINTO, T. P. A longa travessia na formação de professores. LINHA MESTRA. n.31, p.31-39, 2017. Disponível em $<$ http://https://linhamestra31.wordpress.com/2017/03/02/revista-linha-mestra-ano-xi-no-31jan-abr-2017-issn-1980-9026/>. Último acesso em: 01 ago. 2018.

SNAPPER, E. As três crises da Matemática: o logicismo, o intuicionismo e o formalismo. Revista Humanidades, v. II, n. 8, pp. 85-93, 1984. 
TRAVIS. When I'm feeling blue. In. Happy, 1997.

THE VELVET UNDERGROUND. Linger on your pale blue eyes. In. The Velvet Underground. 1969

VILELA, D. S. Matemáticas nos usos e jogos de linguagem: ampliando concepções na Educação Matemática. Tese de Doutorado - Universidade Estadual de Campinas, Campinas, 2007.

WITTGENSTEIN, L. Investigações Filosóficas. Tradução José Carlos Bruni. São Paulo: Nova Cultural, 1999.

WITTGENSTEIN, L. Investigações Filosóficas. Tradução Marcos G. Montagnoli. Revisão da tradução e apresentação Emmanuel Carneiro Leão. 6ª ed. - Petrópolis: Vozes, 2009a.

WITTGENSTEIN, L. Anotações sobre as cores - Edição bilíngue. Tradução de João Carlos Salles Pires da Silva. Unicamp: Campinas, 2009b.

\section{SOBRE O AUTOR}

THIAGO PEDRO PINTO. Professor da Universidade Federal de Mato Grosso do Sul UFMS; Professor do Curso de Licenciatura em Matemática e Professor do Programa de PósGraduação em Educação Matemática (mestrado e doutorado) do INMA; Graduado em Licenciatura em Matemática pela Faculdade Estadual de Filosofia Ciências e Letras de Jacarezinho - PR (2005) atual UENP. Mestre em Educação Matemática pela UNESP - Rio Claro (2009). Doutor em Educação para a Ciência UNESP - Bauru (2013). Desde 2006 está vinculado ao GHOEM, Grupo de História Oral e Educação Matemática. Desde 2011 está vinculado ao Grupo História da Educação Matemática em Pesquisa (HEMEP). Orienta trabalhos vinculados à linha História, Filosofia e Educação Matemática. 